\title{
High Temperature Open Tubular Capillary Column Ion Chromatography
}

\author{
Dongjin Pyo ${ }^{*}$, Purnendu K. Dasgupta ${ }^{*}$, Leon S. YengoyaN ** \\ *Department of Chemistry and Biochemistry, Texas Tech University, Lubbock, TX 79409-1061 \\ ${ }^{+}$Department of Chemistry, Kangwon National University, 200-701, KOREA(Permanent Address) \\ **Department of Chemistry, San Jose State University, San Jose, CA 95192-0101
}

\begin{abstract}
Construction and preliminary characterization of open tubular capillary column ion chromatography is described. Increasing the column temperature resulted in a dramatic increase of the column efficiency. Two different kinds of columns were developed and investigated for capillary ion chromatography. One was a $50 \mu \mathrm{m}$ i.d. fused silica capillary tubing, and another was a $50 \mu \mathrm{m}$ i.d. silica capillary coated with Latex particles (diameter: about $360 \mathrm{~nm}$ ). Both columns showed good separations of inorganic anions, although the capillary coated with Latex particles showed much larger retention than a bare silica capillary.
\end{abstract}

Keywords Ion chromatography, capillary column

Ion chromatography (IC) was first introduced in 1975 by Small, Stevens, and Baumann ${ }^{1}$ as a new analytical method. Within a short period of time, ion chromatography was developed from a new detection scheme for a few selected inorganic anions and cations to a versatile analytical technique for ionic species in general. However, the separation efficiency of IC is lower than that of high performance liquid chromatography (HPLC). This is because the kinetics of ion exchange processes are often slow. One of the goals of this study is to develope the best means of achieving high separation efficiencies in IC. For a even stationary phase, there are two general ways to improve the column efficiency per unit length in liquid chromatography; one is to use a smaller diameter column and the other is to increase the column temperature.

There is now a great deal of interest in the use of small bore columns to improve column efficiency in LC. Both experimental ${ }^{2}$ and theoretical studies ${ }^{3}$ demonstrate it is possible to achieve very high plate efficiencies ( up to nearly $10^{6}$ plates ) using small bore columns, either small bore packed columns, packed capillary columns, or open tubular capillary columns. Among these, open tubular columns offer several unique advantages such as high efficiency, high speed and excellent permeability.
Open tubular columns in LC (OTLC) were first investigated by Ishii, Tsuda, and coworkers ${ }^{4-6}$ following pioneering work by Nota, et. al. ${ }^{7}$. In theory, as shown by Knox and Gilbert ${ }^{8}$, the bores of such columns must be in the range of 10-30 $\mu \mathrm{m}$ if they are to compete with packed columns in terms of speed and performance generally. However, others $^{9,10}$ reported that the optimum internal diameters in open tubular capillary LC columns would be less than $10 \mu \mathrm{m}$ to realize acceptable analysis time and high resolution. Such small i.d. open tubular columns are, very difficult to work with, since their volumn is less than $1 \mu \mathrm{L}$, which places extremely high demands on instrumentation, such as injection, pumping, connection and especially detection. On column electrochemical detectors have been used to obtain small detection volumes and fast response ${ }^{11}$. Although the chief advantages of $1-10 \mu$ $m$ i.d. columns have been demonstrated ${ }^{12,13}$, practical problems mentioned above have limited the wide use of such a small i.d. columns. These practical problems arise because of the very low volumes of the eluted peaks which demand injection and detection systems which themselves produce exceedingly small extra-column band broadening. To date, these technical problems have limited OTLC to about $50 \mu$ 
$\mathrm{m}^{3,14}$ bore columns. Steenackers and Sandra ${ }^{14}$ reported that they could get a high efficiency separations for some polar solutes including proteins using $50 \mu \mathrm{m}$ i.d. open tubular columns.

The effect of high column temperature on separation efficiency has been investigated both experimently ${ }^{15,16}$ and theoretically ${ }^{17}$ by many authors. Diffusion coefficient $\left(D_{m}\right)$ of the analyte in the mobile phase is increased with increasing temperature, and an increase in $D_{m}$ improve the efficiency. It is reported ${ }^{18}$ that high temperature is beneficial for both packed column chromatography and OTLC. Liu et. al. ${ }^{2,19}$ recently demonstrated that high temperature $\left(100-200^{\circ} \mathrm{C}\right)$ operation with $50 \mu \mathrm{m}$ and $100 \mu \mathrm{m}$ i.d. OTLC permit very high efficiency separations (up to $10^{6}$ plates) for organic compounds.

Despite all the advantages of OTLC, reports on open tubular ion chromatography (OTIC) are rare. Muller et. al. ${ }^{12,13}$ used $2.3 \mu \mathrm{m}$ and $4.6 \mu \mathrm{m}$ i.d. open tubular column to separate inorganic anions and cations with their specially designed on-column electrochemical detectors. Several explanations for this situation are possible; one would be the low column efficiency when operated at room temperature, another would be the difficulty in making appropriate open tubular ion chromatographic columns. This paper demonstrates that these difficulties can be overcome by well prepared columns, the choice of appropriate eluent and operation at elevated of column temperature.

\section{Experimental}

The open tubular column ion chromatography instrument used in this study was constructed in our laboratory. A schematic of the instrument is shown in Fig. 1. It consisted of a Shimazu GC-8A oven for the control of the column temperature, a Dionex 2000i pump, a Rheodyne Model 7000 injector (injection volume: $5 \mu \mathrm{L}$ ), two split tees (Valco $1 / 16$ inches, $0.75 \mathrm{~mm}$ bore), a UV or a conductivity detector, a $50 \mu \mathrm{m}$ i.d. capillary column (length: $3 \mathrm{~m}$ or $6 \mathrm{~m}$ ) and a $20 \mu \mathrm{m}$ i.d. capillary restrictor (length: $1 \mathrm{~m}$ ).

Two splitters were used to provide a fairly low flow rate (usually about $1 \mu \mathrm{L} / \mathrm{min}$ ) for $50 \mu \mathrm{m}$ i.d. open tubular capillary column. The first splitter in which a tube of $10 \mathrm{~cm} \times 20 \mu \mathrm{m}$ i.d. fused silica capillary was used as the split tube, was placed between the pump and the preheating tube. The split ratio of the first splitter was about 1:10. The second splitter in which $1.3 \mathrm{~m} \times 75 \mu \mathrm{m}$ i.d. fused silica capillary was used as the split tube giving a split ratio about 60 was placed inside the oven. To avoid the extra-column broadening due to a splitter, the column inlet was inserted into $20 \mathrm{~cm} \times 0.030$ inches stainless steel tubing which connects between the injector and the second splitter. A preheating tube $(50 \mathrm{~cm} \times 0.25 \mathrm{~mm}$ i.d. stainless steel tube) was used to preheat the eluent before column and placed between the first splitter and the injector inside the oven.

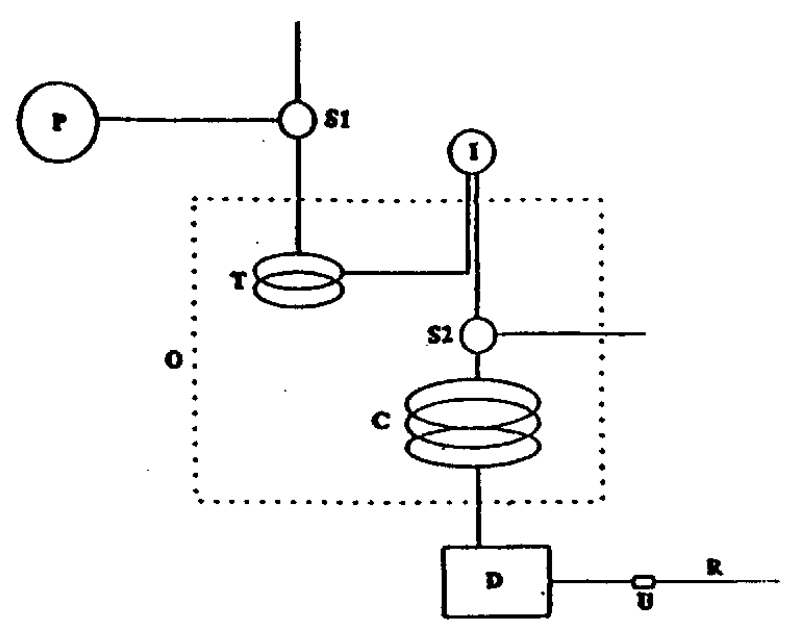

Fig. 1 Schematic diagram of open tubular capillary column Ion chromatographic system: P, IC pump; S1, first splitter, S2, second splitter, I, injector, T, preheating tube; $C$, column; $D$, detector, $R$, restrictor; $\mathbf{O}, G C$ oven; U, union.

A variable wavelength absorbance detector, a Model $\mathrm{CV}^{4}$ (Isco, Inc, Lincoln, NE) was utilized to measure the absorbance at $210 \mathrm{~nm}$. The detection was carried out by measuring the absorbance on the column at a position $15 \mathrm{~cm}$ from the end of the capillary tube. When the surfactants of bromide form were used as eluants, conductivity detection was employed. A conductance cell with narrow bore tubings developed in our laboratory ${ }^{20}$ was used with Dionex conductivity detector (CDM-I). All separations were performed in fused silica capillary purchased from Polymicro Technologies (Phoenix, $\mathrm{AZ}$ ) and which had the following dimensions: i.d. 50 $\mu \mathrm{m}$ and o.d. $360 \mu \mathrm{m}$.

To maximize the number of active surface silanol group on the inner wall of the fused silica capillary, the rinsing procedure developed by Muller et. al. ${ }^{13}$ was employed with slight modifications. In brief, first, the $50 \mu \mathrm{m}$ i.d. fused silica capillaries were rinsed with a mixture of hydrofluoric and nitric acids (about $2.5 \%(\mathrm{v} / \mathrm{v})$ and $2.5 \%(\mathrm{v} / \mathrm{v})$ respectively) for $30 \mathrm{~min}$ 
afterwards with $1 \%(w / v)$ hydrochloric acid for 30 min. As a final pretreatment step, the capillaries were rinsed with water to neutrality.

All reagents were of analytical grade and used without further purification. The surfactants, CTAC (cetyltrimethylammonium chloride), CTAB (cetyltrimethylammonium bromide), OTAB (octadecyl trimethylammonium bromide), tetrahexyl ammonium bromide, tetrabutyl ammonium bromide were obtained from Aldrich Chemical Co. (Milwaukee, WI). Cetyltrimethylammonium acetate was prepared in the laboratory by passing CTAC through the column of strong anion exchangers of acetate form. Standard solutions of inorganic anions were prepared by dissolving potassium salts with water.

As mentioned before, the open tubular capillary columns have quite small internal volumes, e.g., the column of $3 \mathrm{~m} \times 50 \mu \mathrm{m}$ i.d. has a volume of $6 \mu \mathrm{L}$. To use such columns in IC, the apparatus should be able to ${ }^{21}$; (A) pumping the mobile phase at very low flow rates (B) load a small amount of sample (C) connect the capillaries so as not to cause additional band broadening and (D) use an appropriately small detection volume.

\section{Results and Discussion}

\section{Use of bare silica capillaries as a column}

Since there exist free silanol groups on the surface of inner wall of bare silica capillaries, it is possible to make a capillary inner wall modification by adding positively charged surfactants in the mobile phase. The negatively charged inner surface of a fused silica capillary can be coated dynamically with a layer of positively charged surfactants. Several cationic surfactants such as CTAC (cetyltrimethylammonium chloride), CTAB (cetyltrimethylammonium bromide), OTAB (octadecyltrimethylammonium bromide), tetrahexyl ammonium bromide, tetrabutyl ammonium bromide, and cetyltrimethylammonium acetate were used for this study. It is clear that these cationic surfactants can adsorb to the surface silanol groups of bare silica capillary, and this dynamic modifications of silica surface can provide a pseudostationary phase for anion separations. The effects of the surfactant modified silica capillary were evaluated by comparing the chromatographic behavior of several anions mixture. For example, when $1.8 \mathrm{mM}$ CTAC was used as a surfactant, and $3 \mathrm{~m} \times 50 \mu \mathrm{m}$ i.d. bare silica capillary was employed as a column, several inorganic ions such as iodate, nitrite, nitrate and iodide are well separated both at room temperature and at $100^{\circ} \mathrm{C}$ (Fig. 2)

Adsorptions of different surfactants on the inner wall of silica capillaries change the retention behaviors of analyte ions. Retention data with different carbon chain size surfactants $\left(\mathrm{R}_{4} \mathrm{~N}^{+}\right)$are shown in Table 1. It is seen that as the length of carbon chains of $\mathrm{R}_{4} \mathrm{~N}^{+}$used increase, retentions of analyte anions increase. The data in Table 1 suggests to us that total carbon number of $\mathrm{R}_{4} \mathrm{~N}^{+}$is not an important parameter in retention behaviors of analyte anions, the length of the longest carbon chain in $\mathrm{R}_{4} \mathrm{~N}^{+}$ is important. The type of anions accompanying the $\mathrm{R}_{4} \mathrm{~N}^{+}$salt could also influence retention of analyte anions. The effect of $\mathrm{R}_{4} \mathrm{~N}^{+}$coanion is shown in Table 2. It is seen that the effect of coanions in increasing the anlyte retention follows the order Acetate $>$ Chloride $>$ Bromide. These results agree with other results in the literature ${ }^{22,23}$.
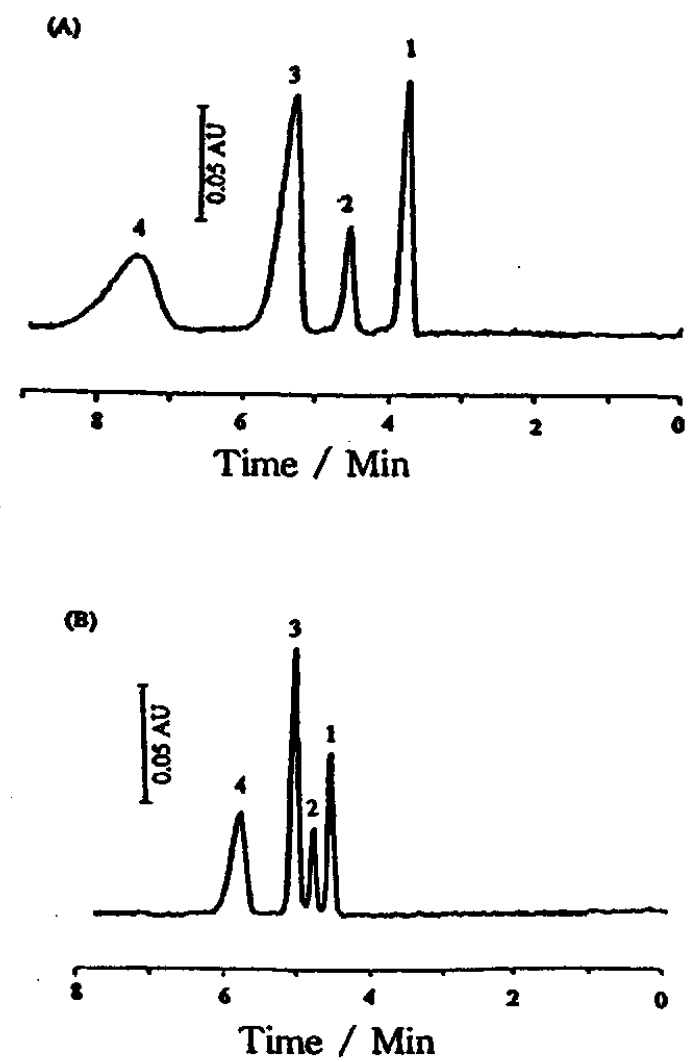

Fig. 2 Chromatograns of anions mixture showing temperature effect on separation efficiency. Column: $3 \mathrm{~m}$ $\times 50 \mu \mathrm{m}$ i.d. bare silica capillary, Eluent: $1.8 \mathrm{mM}$ CTAC, Detector: UV detector at $210 \mathrm{~nm}$, Peaks: 1=iodate, 2=nitrite, 3=nitrate, 4=iodide, Temperature: (A) $25^{\circ} \mathrm{C}$ and (B) $100^{\circ} \mathrm{C}$. 
Table 1 Capacity factors of anions in the presence of $2 \mathrm{mM}$ tetraalkylammonium surfactants with different size of carbon chain length.

\begin{tabular}{lcc}
\hline \multicolumn{1}{c}{ Surfactant } & $\mathbf{k}^{\prime}$, Chlorate & $\mathrm{k}^{\prime}$, Benzoate \\
\hline $\begin{array}{l}\text { Hexadecyltrimethylammonium } \\
\text { bromide }\end{array}$ & $0.18 \pm 0.01$ & $0.32 \pm 0.01$ \\
$\begin{array}{l}\text { Octadecyltrimethylammonium } \\
\text { bromide }\end{array}$ & $0.66 \pm 0.03$ & $0.83 \pm 0.02$ \\
$\begin{array}{l}\text { Tetrahexylammonium bromide } \\
\text { Tetrabutylammonium bromide }\end{array}$ & $0.14 \pm 0.01$ & $0.23 \pm 0.01$ \\
\hline
\end{tabular}

Table 2 Capacity factors of anions in the presence of $2 \mathrm{mM}$ tetraalkylammonium surfactants with different coanions.

\begin{tabular}{lcc}
\hline \multicolumn{1}{c}{ Surfactant } & k',Chlorate & $k^{\prime}$, Benzoate \\
\hline $\begin{array}{l}\text { Hexadecyltrimethylammonium } \\
\text { bromide }\end{array}$ & $0.18 \pm 0.01$ & $0.32 \pm 0.01$ \\
$\begin{array}{l}\text { Hexadecyltrimethylammonium } \\
\text { chloride }\end{array}$ & $0.26 \pm 0.01$ & $0.60 \pm 0.01$ \\
$\begin{array}{l}\text { Hexadecyltrimethylammonium } \\
\text { acetate }\end{array}$ & $0.48 \pm 0.01$ & $0.75 \pm 0.02$ \\
\hline
\end{tabular}

The effect of column temperature on efficiency in open tubular capillary column IC was investigated with $3 \mathrm{~m} \times 50 \mu \mathrm{m}$ i.d. fused silica capillary as a column (Table 3). The mobile phase was $1.8 \mathrm{mM}$ CTAC in water. Flow rate was about $1 \mu \mathrm{L} / \mathrm{min}$. From Table 3, it is clearly observed that the column efficiency is greatly increased with increasing column temperature (see Fig. 3). In the case of nitrate, the efficiency at $100^{\circ} \mathrm{C}$ is about 4 times greater than at room temperature, although the capacity factor was decreased with increasing temperature (Table 3). The diffusion coefficient of analyte in the mobile phase increase with increasing temperature, resulting in higher efficiency. It can be easily derived from Eqn (2) that for a given analyte, $u_{o p t}$ is proportional to $D_{m} / d_{c}$ and $N$ is proportional to $\frac{D_{m}}{d_{c}{ }^{2} \cdot u}$. The numbers of plates were increased dramatically with temperature (Fig. 4) since $D_{m}$ markedly with increases temperature.
Table 3 Effects of column temperature on capacity factors and plate numbers using a $3 \mathrm{~m} \times 50 \mu \mathrm{m}$ i.d. bare silica capillary as a column.

\begin{tabular}{cccccccc}
\hline \multirow{3}{*}{$\begin{array}{c}\text { Column } \\
\text { temp. }\end{array}$} & napacity factor & \multicolumn{5}{c}{ Number of theoretical plates } \\
\cline { 2 - 7 } & nitrate & iodide & nitrite & nitrate & iodide \\
\hline $25^{\circ} \mathrm{C}$ & 0.26 & 0.49 & 1.07 & 7791 & 2941 & 914 \\
$70^{\circ} \mathrm{C}$ & 0.13 & 0.25 & 0.68 & 15512 & 7519 & 2805 \\
$80^{\circ} \mathrm{C}$ & 0.099 & 0.20 & 0.51 & 21756 & 8610 & 3408 \\
$90^{\circ} \mathrm{C}$ & 0.085 & 0.15 & 0.35 & 27745 & 9793 & 3962 \\
$100^{\circ} \mathrm{C}$ & 0.068 & 0.11 & 0.26 & 33274 & 11728 & 4600 \\
$110^{\circ} \mathrm{C}$ & 0.062 & 0.082 & 0.19 & NC & 13273 & 5628 \\
$120^{\circ} \mathrm{C}$ & 0.047 & 0.061 & 0.14 & NC & 15429 & 6530 \\
\hline
\end{tabular}

Therefore, as Liu et. al. ${ }^{2}$ pointed out, for aquous systems, an increase in column temperature from 25 to $100 \mathrm{C}$ has the similiar effect in improving the efficiency as a decrease in column diameter from $\mathbf{5 0}$ to $25 \mu \mathrm{m}$. An increase in column temperature from 25 to 100 results in an estimated increase in $D_{m}$ by 4.03. [ $\frac{D_{m, 100}}{D_{m, 25}}=\frac{\eta_{25}}{\eta_{100}}\left(\frac{373}{293}\right)=4.03$, where $D_{m, 100}$ and $D_{m, 25}$ are the diffusivities of the solute and $\eta_{100}$ and $\eta_{25}$ are the viscosities of water at 100 and $25^{\circ} \mathrm{C}$ respectively]

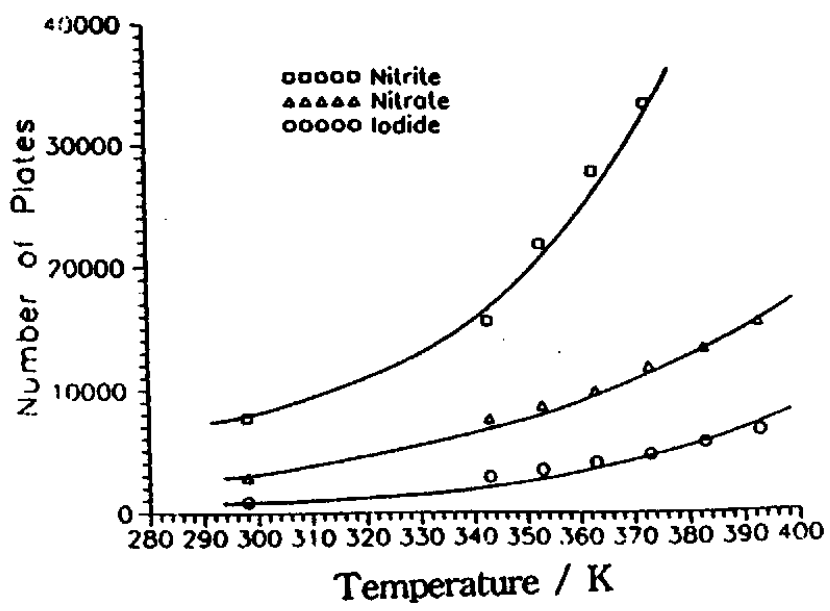

Fig. 3 Number of theoretical plates of anions measured at different column temperatures. Column: $3 \mathrm{~m} \times 50 \mu \mathrm{m}$ i.d. bare silica capillary, Eluent: $1.8 \mathrm{mM}$ CTAC, Detector: $\mathrm{UV}$ detector at $210 \mathrm{~nm}$.

Use of a capillary coated with Latex particles as a column 
Although a bare silica capillary as a column showed a good performance, the absolute retentions of analyte anions were rather small (Table 3 ). To overcome these drawbacks, we made a new type of open tubular capillary columns for IC by use of latex particles. Latex particles were first introduced in 1975 by Small et. al. ${ }^{24}$. Latex particles used in the results described below were supplied by Dionex and have a very small diameter (about $375 \mathrm{~nm}$ ) and carry the actual anion exchange groups. These particles are agglomerated to the silanol groups on the inner surface of fused silica capillary by electrostatic interactions. Before the capillary was treated with a solution of the latex particles, the capillary was cleaned with several reagents to produce the maximum number of active surface silanol groups described in the experimental section. The coating procedure involved flushing the capillary with a solution of the latex particles. As expected, the capillary coated with latex particles showed much greater retention without sacrificing efficiencies both at room temperature and at high temperatures (see Table 4). Improvement of efficiencies with increasing temperature and the reduction of capacity factors with increasing temperature were observed also with these latex particles coated columns. Another interesting observation was the change in peak shape of the highly retained species at higher temperatures. Figure 4 shows the peak shape of iodide ion was improved at higher column temperatures. The decrease of retention at higher temperature has also been observed in other OTLC studies $^{2}$. Exact performance of the latex coated capillaries not only depends on the latex but also on the capillary and can vary greatly from one batch to another. The advantages of the latex coated capillary over the bare silica capillary are the follows: (A) higher retention (B) higher capacity (C) compatibility can be used with suppressed conductometric detection.

Table 4 Effects of column temperature on capacity factors and plate numbers using a $6 \mathrm{~m} \times 50 \mu \mathrm{m}$ i.d. capillary coated with latex particles as a column.

\begin{tabular}{ccccccc}
\hline \multirow{2}{*}{$\begin{array}{c}\text { Column } \\
\text { temp. }\end{array}$} & \multicolumn{3}{c}{ Capacity factor } & \multicolumn{5}{c}{ number of theoretical plates } \\
\cline { 5 - 8 } & nitrate & iodide & nitrite & nitrate & iodide \\
\hline $25^{\circ} \mathrm{C}$ & 0.54 & 1.17 & 4.94 & 2702 & 2405 & 906 \\
$50^{\circ} \mathrm{C}$ & 0.43 & 0.85 & 2.46 & 4038 & 3716 & 1234 \\
$70^{\circ} \mathrm{C}$ & 0.26 & 0.50 & 1.35 & 5617 & 5428 & 3493 \\
$90^{\circ} \mathrm{C}$ & 0.20 & 0.39 & 1.07 & 7201 & 7143 & 5071 \\
$110^{\circ} \mathrm{C}$ & 0.16 & 0.28 & 0.73 & 8523 & 8470 & 6851 \\
$130^{\circ} \mathrm{C}$ & 0.13 & 0.22 & 0.52 & 11357 & 10677 & 9826 \\
$150^{\circ} \mathrm{C}$ & 0.10 & 0.16 & 0.38 & NC & 15367 & 15108 \\
\hline
\end{tabular}
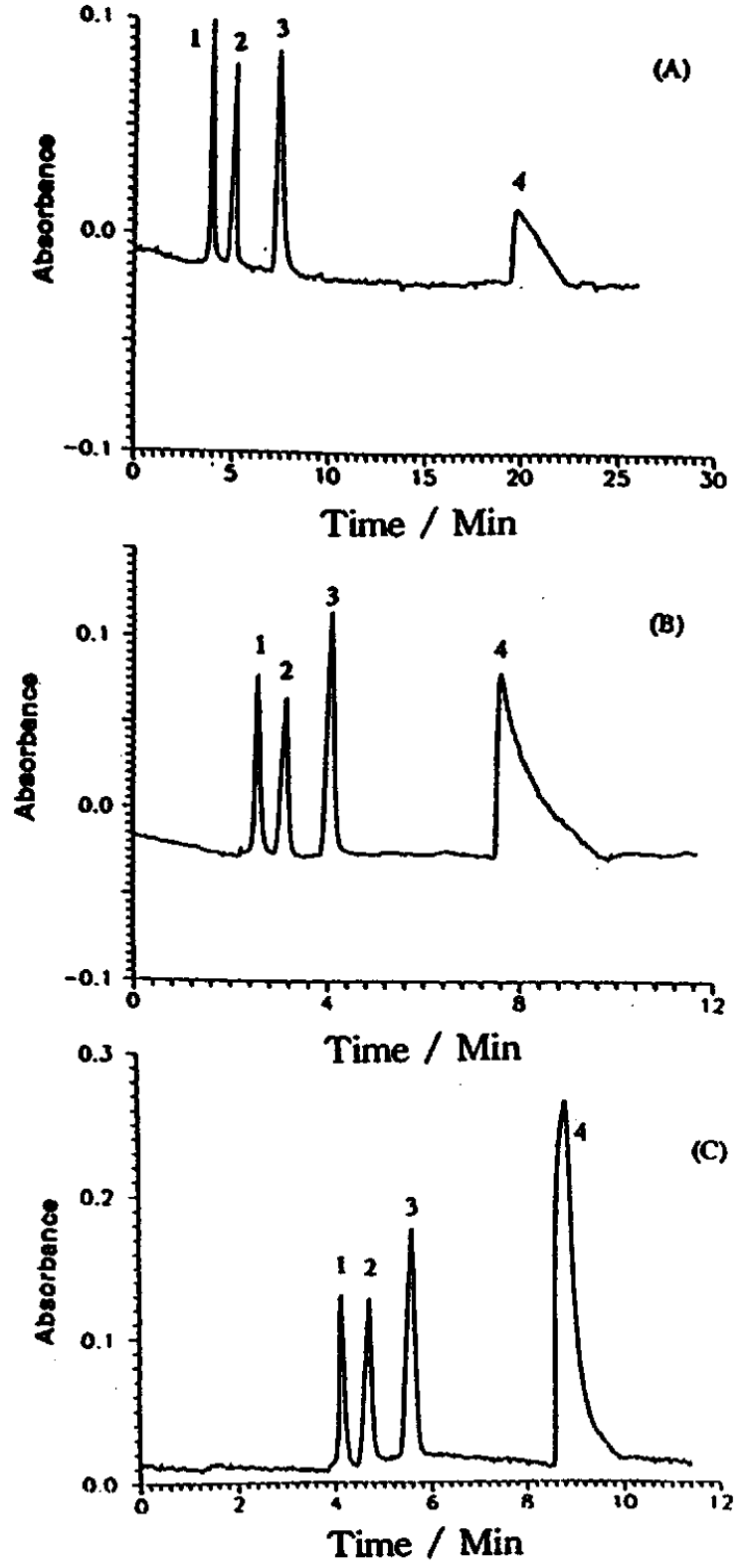

Fig. 4 Chromatograms of anions mixture showing temperature effect on peak shape. Column: $6 \mathrm{~m} \times 50 \mu \mathrm{m}$ i.d. capillary coated with latex particles, Eluent: $0.3 \mathrm{mM}$ sodium sulfate, Detector: UV detector at 210nm, Peaks: 1=iodate, 2=nitrite, 3=nitrate, 4=iodide, Temperature: (A) $25^{\circ} \mathrm{C}$, (B) $50^{\circ} \mathrm{C}$ and (C) $70^{\circ} \mathrm{C}$.

This research was supported by the US Department of Energy, Office of Basic Energy Sciences, Division of Chemical Sciences through grant DE-FG03-95ER14496, and also partially supported by Ministry of Education, Korea (BSRI-96-3425). However, this manuscript has 
not been subject to review by the DOE and no endorsements should be inferred.

\section{References}

1. Small, H.;Stevens, T.S.; Baumann, W.C. Anal. Chem., 47, 1801 (1975).

2. G. Liu, G.;Djordjevic, N.M.;Emi, F. J. Chromatogr., 592, 239 (1992).

3. Knox, J.H. J. Chromatogr. Sci., 18, 453 (1980).

4. Tsuda, T.; Hibi, K.; Nakanishi T.: Takeuchi, T.; Ishii, D. J. Chromatogr., 158, 227 (1987).

5. Tsuda, T.; Novotny, M. Anal. Chem., 50, 632 (1978).

6. Ishii, D.; Tsuda, T.; Takeuchi, T. $J$. Cromatogr., 185, 73 (1979).

7. Nota, G.; Marino, G.; Buonocore, V.; Ballio, A. J. Chromatogr., 46, 103 (1970).

8. Knox, J.H.; Gilbert, M.T. J. Chromatogr., 186, 405 (1979).

9. Jorgenson, J.W.; Guthrie, E.J. J. Chromatogr., 255, 335 (1983).

10. Scott, P.W. J. Chromatogr., 517, 297 (1990).

11. Manz, A.; Simon, W. J. Chromatogr., 387, 187 (1987).

12. Muller S.R.; Simon, W.; Widmer. H.M.; Grolimund, K.; Schomburg, G.; Kolla, P. Anal. Chem., 61,2747 (1989).

13. Muller S.; Scheidegger, D.; Haber, C.; Simon, W. J. High Resolut. Chromatogr., 14, 174 (1991).

14. Steenackers, D.; Sandra, P. J. High Resolut. Chromatogr., 17, 557 (1994).

15. Tsuji, K.; Goetz, J.F. J.Chromatogr., 157, 185 (1978).

16. Herbut, G.; Kowalczyk, J.S. J. High Resolut. Chromatogr. Chromatogr. Commun., 4, 27 (1981).

17. Antia, F.D.; Horvath, Cs. J. Chromatogr., 435, 1 (1988).

18. Erni, F. J. Chromatogr., 507, 141 (1990).

19. G. Liu, G.;Djordjevic, N.M.;Erni, F.J. Chromatogr., 598, 153 (1992).

20. Qi, D.; Okada, T.; Dasgupta, P. Anal. Chem., 61, 1383 (1989).

21. Ishii, D.; Takeuchi, T. J. Cromatogr. Sci., 18, 462 (1980).

22. Iskandarani, Z.; Pietrzyk, D.J. Anal. Chem., 54, 1065 (1982).
23. Bidlingmeyer, B.A.; Deming, S.N.; Price, W.P.; Sachok, B.; Petrusek, M. J. Chromatogr., 186, 419 (1979).

24. Small H.; Stevens, T.S.; Baumann, W.C. Anal. Chem., 47, 1801 (1975). 